\title{
SITUATING COMMUNICATIVE PLANNING THEORY: CONTEXT, POWER AND KNOWLEDGE
}

\author{
P.M. $\mathbf{M}^{\mathrm{c}}$ Guirk \\ Discipline of Human Geography \\ School of Geosciences \\ The University of Newcastle \\ Callaghan \\ NSW 2308
}

Email: ggpmm@cc.newcastle.edu.au

Word count 10262

(plus 304 word footnotes and 199 word abstract) 


\title{
SITUATING COMMUNICATIVE PLANNING THEORY: CONTEXT, POWER AND KNOWLEDGE
}

\begin{abstract}
The purpose of this paper is to contribute to an emerging body of critique of communicative planning theory (CPT). The paper's critiques are grounded in analysis of situated planning practice in Newcastle, New South Wales, Australia, where planners were 'feeling their way towards' democratising planning practice in line with CPT's normative dimensions. Two critiques are offered. Both are fundamentally concerned with power and the tendency of CPT to operate as if the workings of power can be temporarily suspended through communicative planning practice to produce new consensual planning discourses. Firstly, it is argued that CPT pays insufficient attention to the practical context of power in which planning is practised thereby assuming away, rather than engaging with, the politics- and power-laden interests that infiltrate planning practice. Secondly, it is argued that CPT abstracts planners from their positioning in a nexus of power, knowledge and rationality which validates expert forms of knowing/reasoning/valuing, and thus underestimates the challenges of asserting alternative forms. The paper concludes by suggesting that any theory aiming at the democratisation of planning practice will need to depart from an orientation to consensus, a defining feature of CPT, and instead account for the irreducible nature of power and difference.
\end{abstract}




\section{Introduction ( $\left.\mathbf{1}^{\text {st }}\right)$}

The founding epistemologies of planning theory have recently been challenged by cultural diversity, a strengthening civic society, and philosophical critiques emerging largely from postmodernism's deconstructive, antifoundational and pluralistic tendencies (Filion, 1996; Moore Milroy, 1991; Sandercock, 1998). Communicative planning theory (CPT) has emerged in response to these challenges. While it is difficult to capture under the rubric of $a$ theory, CPT's proponents (Forester, 1989; Hoch, 1994; Sager, 1994; Innes, 1995; Healey, 1997) cite as it core aim the democratisation of planning practice and the empowerment of discourse communities, forms of reasoning, and value systems heretofore excluded from planning practice. These exclusions are seen to arise from the dominatory power relations of instrumental rationality, modernist planning's founding epistemology. Thus, unlike many critiques of, and attempts to democratise, planning practice (Davidoff, 1965; Arnstein, 1969; Goodman, 1972), CPT addresses planning's epistemological foundations (Sandercock, 1998) and as such its implications for planning practice are substantial, and it has been claimed that CPT is achieving paradigmatic status (Innes, 1995) and driving best practice in planning.

Nonetheless CPT remains problematic (see e.g. Tewdwr-Jones and Allmendinger, 1998; Allmendinger, 1999; Hiller, 2000; Huxley 2000; Huxley and Yiftachel, 2000; Phelps and Tewdwr-Jones, 2000). The purpose of this paper is to reflect on the problematic implications of pursuing normative dimensions of CPT in the actual politics and power relations of practice. The paper draws on an analysis of situated planning practice in Newcastle, New South Wales, Australia, in which planners have been 'feeling their way towards' democratising planning practice in accordance with CPT's central precepts (Tewdwr-Jones and Thomas, 1998). This analysis is used to explore two critiques. It is argued firstly that CPT pays insufficient attention to the practical context of power relations in which planning practice is situated, thereby assuming away, rather than engaging with, the politics- and power-laden interests that infiltrate planning deliberation. Secondly, it is argued that CPT abstracts planners from their positioning in a nexus of power, knowledge and rationality in which their professional forms of knowing, reasoning and valuing are validated, and thus CPT underestimates the challenges of asserting alternative forms. The paper concludes by suggesting that any theory aiming at the democratisation of planning practice will need to depart from an orientation to consensus, a defining feature of CPT. Instead, it will need to account for the irreducible nature of power and difference, and focus on the question of how 
to plan democratically in the context of conflict.

\section{Communicative planning theory and practice $\left(1^{\text {st }}\right)$}

\section{Building practice through communicative rationality $\left(2^{\text {nd }}\right)$}

CPT builds its case for renewing planning practice on a critique of planning's epistemological foundations. The theory identifies the epistemology underpinning modernist planning practice as deriving from instrumental rationality, understood as planning's defining rationality. This epistemology produces a planning practice in which knowledge is constructed predominantly through techno-scientific analysis and deductive logic, and through the privileging of voices which appeal to these forms of knowing/reasoning. A range of knowledge forms and value systems are excluded from such a practice: experiential, local, intuitive, tacit and expressive knowledges which draw on the moral or aesthetic realms rather than solely on the realms of scientific logic and empiricism (Healey, 1997; Innes, 1998).

CPT's normative aim is to replace instrumental rationality with Habermas' (1984) notion of communicative rationality. Habermas draws a distinction between instrumental rationality's subject-object conception of reasoning and a form of reasoning generated reflexively through inter-subjective deliberation and argumentation — that is, communicative rationality. Communicative rationality is said to draw on subjects' practical consciousness in which the world of physical things, the world of inner experience and the social world of roles and norms overlap (Healey, 1993: Outhwaite, 1994). Thus meaning, value, understanding and knowledge are generated inter-subjectively and through deliberation that draws on diverse forms of knowing, reasoning and representation. Thus in CPT, knowledge is:

'not a pre-formulated store of systematised understandings but is specifically created anew in our communication through exchanging perceptions and understandings and drawing on stocks of life experiences and previously consolidated cultural and moral knowledge available to participants' (Healey, 1993, page 241).

Communicative rationality involves acceptance of the social construction of meaning, the social embeddedness of ways of thinking and acting in varied discourse communities, and the interpretive nature of the world (Healey, 1997; Innes and Booher, 1998). It involves collaborative and reflexive processes of building consensus around shared meanings and understandings which are grounded in dialogue. Thus it is dramatically opposed to instrumental rationality and its processes of creating knowledge and ascribing value.

Inserting communicative rationality at the core of planning would create a new form of 
practice which would aim to ensure that forms of knowledge, reasoning and representation beyond those central to instrumental rationality are brought into the process. This communicative planning practice (CPP) would nurture deliberation between discourse communities, understood as being framed in varied cultural systems of meaning. Through a social process of rational argumentation in which 'ear, voice and respect' (Dryzek, 1990) are ensured for all stakeholders and value systems, the 'force of better argument' (Outhwaite, 1994) would enable new understandings and new consensual systems of meaning to be generated communicatively.

Thus, CPP's outcomes would not be oriented to the pursuit of instrumental or strategic interests. Such interests would be identified through argumentation and rejected on the grounds of their partiality. Instead, impartial generalised interests would be collectively derived through deliberation aimed at establishing new sets of collective values and a new 'shared language' (Healey, 1998a, page 13). Ultimately, a new consensual policy discourse for planning could flow which would frame specific planning actions, strategies and regulatory decisions. Consequently, communicative planning becomes a 'deeply social process of making sense together' (Forester, 1989, page 119). It aims to enable a multi-cultural planning policy discourse to develop which is capable of attending to claims from diverse systems of meaning and modes of reasoning, moral perspectives, cultural expressions and material conditions (Healey, 1993; Healey and Hillier, 1996; Rein and Schon, 1993). Thus the planning practice which emerges communicative rationality is fundamentally aimed at generating consensual 'ways of thinking, ways of valuing and ways of acting (Healey, 1997, page 29).

\section{Power and 'the finegrain of practice' $\left(2^{\text {nd }}\right)$}

CPT's orientation to consensus raises two important questions. The first of these is how to deal with the uneven power relations which infuse planning practice? CPT accepts that power infiltrates every dimension of planning and 'enters the finegrain of practice' (Healey, 1997, page 5). Indeed, the theory adopts a Giddensian conceptualisation which recognises power as being carried in the policy discourses, institutional practices, structural forms, cultural systems and social relations which contextualise planning practice. Thus planning is a politics- and power-laden practice taking place in 'an organisational and political context in which the agendas of decision making are politically and selectively structured; and citizens 
cannot participate equally in decisions affecting them' (Forester, 1989, page 139). However, the purpose of CPP is to transform power relations by creating deliberative forums which can (temporarily) negate the power context of planning — the inequalities that stakeholders bring with them on entering participatory processes. These power-neutral forums are aimed to produce, however temporarily, a 'shared-power-world' (Bryson and Crosby, 1992) in which the relations of power that inhere in communication might be transformed.

Here, CPT draws on the Habermasian concepts of 'communicative distortion' and 'ideal speech situations' (Habermas, 1996). In conventional planning, the consensus envisaged above is prevented by the systematic distortion of communication by dominatory power relations (Hillier, 1993; Forester, 1989). Distortion is said to occur when groups seek to extend their power by attempting to restrict argumentation by excluding participants, making unfounded appeals to rationality, strategically obscuring issues or manipulating opinion (see Hillier, 1993; Phelps and Tewdwr-Jones 2000). Crucially, attempts to control decisionmaking, shape agendas, act strategically, pursue instrumental interests, or use persuasion or manipulation - the staple in conventional planning practice-are deemed in CTP to be distortions to be overcome.

In contrast, CPT would minimise communicative distortions which have enabled powerful groups to maintain positions of power (Healey, 1997, page 264), and thus to achieve powerneutrality by approximating Habermas' 'ideal speech situation'. While only imperfectly and temporarily attainable, this ideal speech situation is one in which all relevant interests are represented in deliberation, are equally informed and able to represent themselves, and are equally empowered in discussion. Power differences from other contexts must not be allowed to influence who is listened to or who can speak (Innes, 1998). Only when distortion is minimised can participants be free to deliberate until a series of common meanings and values can be established. In this power-neutral space, planning practice is opened out to democratic deliberative processes through which communicative rationality might be put to effect. Thus, a variety of forms of knowledge, rationality and value can be valorised and new consensusal planning discourses might emerge.

\section{The planner as 'critical friend' $\left(2^{\text {nd }}\right)$}

A second question raised by CPT's orientation to consensus, and which follows on implicitly from the above, concerns how are planners themselves positioned within the politics-infused 
practice of communicative planning? CPT envisages planners as political beings who are cognisant that their organisational and political contexts are characterised by strategising and systematic communicative distortions in which information and the ability to act on it are unevenly distributed (Forester, 1989; Hillier 1993). Thus, planners' role is cast as that of 'critical friend' (Forester, 1996; Healey, 1997; Innes 1995) whose primary task is to deal with 'misinformation', the source of communicative distortion. This task involves anticipating and counteracting misinformation; clarifying, elucidating policy options and implications, and challenging misrepresentation and flawed appeals to legitimacy (Innes, 1994; Taylor, 1998). They manage access to debate and manage its communicative routines. They shape attention by assisting participants' reasoning, alternatively down-playing and stressing issues, guiding judgements on how claims are justified and validated, and mediating and negotiating outcomes (see Innes 1995).

Planners' role in CPP is thus one of exposing the power/knowledge/rationality frames that position claims for attention. As knowledge mediators and brokers, they draw on their expert understanding of the procedures, politics, institutions and norms of governance (Healey, 1992) to assemble the necessary resources and enable a policy dialogue to develop (Throgmorton, 1993). Theirs is a highly political role of exploring and mediating multiple and contested claims, which is practised in the context of acknowledged ambiguity and power asymmetry. Theirs is interpretive work which is bound in practical, political, technical and ethical judgements (Hoppe, 1993). Thus in CPP, planners are arbiters of normative standards and guardians of value. They acknowledge and manipulate power relationships, resisting some forms of power and exercising others (Forester, 1999b). The planners' role in CPP is thus central to directing the process of deliberation, shaping its outcomes and expertly mediating the intersection of these outcomes with the governance procedures and institutions which frame planning practice. So planners are lifted out of the framework of instrumental rationality and cast in the role of presiding over the deliberative processes of communicative rationality aimed at producing consensus.

However, as discussed at the outset, two critiques can be made of CPT's orientation to consensus, and its positioning of planners as 'critical friends' enabling this consensus. Both questions are concerned with the extent to which power-neutrality (and thus communicative rationality) is attainable. These questions are addressed through an analysis of the Newcastle case study. First, however, an outline of that case study is provided. 


\section{Formulating inner Newcastle’s Development Control Plans: 'feeling their way towards' communicative planning practice $\left(1^{\text {st }}\right)$}

Case study rationale $\left(2^{\text {nd }}\right)$

This section is concerned with the practical context of power that frames the possibilities and limitations to CPT. Communicative planning theorists have said little about the practicalities of how undistorted communicative action might actually be achieved and how the transformations of value and power relations necessary for the emergence of a consensual discourse based on communicative rationality might occur (Flyvbjerg, 1998a; Huxley, 2000). Likewise theorists have been slow to acknowledge the practical impacts of variations in discursive power between planners whose professional knowledge and technical expertise are already validated and given authoritative status and those actors whose knowledge and values systems are discursively disempowered (see Burgess and Harrison, 1998). This raises important questions about the practical implications of pursuing normative dimensions of CPT in the actual politics and power relations of practice.

The case study of planning practice analysed here concerns the participatory process carried out during 1998 for redrafting the Development Control Plans (DCP) for inner Newcastle, NSW, specifically DCP40 for City West. ${ }^{1}$ Disillusionment with conventional methods of planning has led Newcastle City Council's (NCC) planning team to adopt a more holistic urban management paradigm, addressing environmental, social and economic issues and including a commitment to participatory forms of policy and plan formulation (NCC, 1998b). The team has aimed at developing local participatory capacity and, thus, improving policy ownership. The rhetoric of the holistic, participatory paradigm has infiltrated the political governance culture, making it more receptive to changing participatory procedures and practices (see Crofts, 1998). Thus, a new heterarchic and holistic approach to planning has been implemented through the introduction of place management techniques (Crofts, 1998) and the deployment of enquiry-by-design — a consensus-building interactive process

\footnotetext{
${ }^{1}$ In NSW, DCPs are documents produced by local government against which development applications in each local area are assessed by the relevant planning authority. DCPs provide the detail which supports the statutory policy framework established within local government Local Environmental Plans. These supply broad land use zoning and determine the development status of all sites. State government produces Regional Environmental Plans which provide broader strategic direction for areas considered significant for environmental planning. These are supplemented by State Environmental Planning Policies concerning state policy on specific planning matters (e.g. SEPP 10, Affordable housing provision).
} 
involving deliberative stakeholder workshops which provide the holistic basis for developing planning strategies as well as detailed local plans. The workshops aim to overcome the conflict of adversarial interest politics that has tended to dominate conventional planning practice. Instead, participants are to be involved in negotiating acceptable planning strategies and outcomes in their own terms, drawing on professional advice on resources and institutional limits. Such techniques have been promoted by NSW state government's Department of Urban Affairs and Planning (DUAP, 1999) and enthusiastically pursued by planning staff at Newcastle City Council. A participatory process derived from enquiry-bydesign was used to formulate DCP40.

Though the process was not necessarily understood by planners in the formal analytical terms of СРP, the approach taken to democratising practice aspired towards many of the conditions that Healey (1997) outlines for CPP's implementation. Planners were 'feeling their way towards' CPP (Tewdwr-Jones and Thomas, 1998) in complex institutional and political context. That is, they were developing the 'soft infrastructure' for CPP (the processes of relationship-building, social collaboration, deliberation) while operating within a 'hard infrastructure' (social structuring, legal frameworks, procedures, rules, resources) geared towards conventional planning practice (Healey, 1997). Nonetheless, as this analysis illustrates, planners' attitudes were genuinely geared towards generating inclusive procedures through which multiple voices could be heard and towards enabling meaningful deliberation as a means of generating a consensual policy framework activated and owned by participants.

The purpose of this paper, however, is not to evaluate this case study as a success or failure in terms of СРP. At most, this case represents a step towards developing these practices in the planning process. Nevertheless, the challenges faced by planners and participants in this example are the very challenges facing any attempt at refashioning planning practices and planning epistemologies within extant legal, institutional and political frameworks (see Young, 1990). Any analysis of the practical workings of CPP needs to attend to its regulatory, institutional and political embeddedness. These uneven convergences of 'hard infrastructure' geared towards top-down governance practices and 'soft infrastructure' aimed at bottom-up participatory practices impinge on CPP's practical operation and radical potential (TewdwrJones and Allmendinger, 1998). Therefore the case study analysis presents an opportunity to reflect on and raise questions about the possibilities of CPT. 


\section{The politics and power relations of practice $\left(2^{\text {nd }}\right)$}

Newcastle has been struggling to deal with structural economic adjustment and to address the city's image as an industrial city in decline (see $\mathrm{M}^{\mathrm{c}} \mathrm{Guirk}$ et al., 1998). In 1992, the NSW state government established the Honeysuckle Development Corporation (HDC) as a special purpose agency $^{2}$ to oversee the redevelopment of 25 hectares of former-industrial publicly owned waterfront land in inner city Newcastle. After eight years and A\$100m of public investment, private development investment is only now being attracted on any significant scale. Pressure to produce visible development outcomes on the site has been intense. The HDC had long argued that existing local planning frameworks were a factor in restraining development. Formulating new inner city DCPs had become a priority in this politically charged context, ensuring that DCP40 for City West, which incorporates the HDC land, was the first DCP to be reformulated in a city-wide DCP review.

\section{INSERT FIGURE 1 (MAP OF DCP 40 AND THE HONEYSUCKLE SITE)}

Stage 1: Managing the process of deliberation $\left(3^{\text {rd }}\right)$

In early 1998, an assessment of development progress in inner Newcastle was commissioned by NCC and the HDC. This assessment was used as a starting-point for a two-day workshop to develop a series of strategies for the inner city and, more specifically, to generate policy reasoning to frame new DCPs. The workshop brought together sixty or so participants considered to represent the key stakeholder groups, including representatives from residents' groups, business, property and industrial interests, service and infrastructure providers, academics and councillors.

The workshop's procedures were designed as means of triggering inclusive debate or, in CPT terminology, of enabling communicative rationality to develop. It began with a presentation on the assessment document which suggested that progress on most development targets had been poor and that development densities beyond those permitted by existing DCPs would be needed if existing development targets were to be reachable. This was

\footnotetext{
2 The Honeysuckle Development Corporation was given powers to masterplan the redevelopment, to undertake infrastructural development on publicly owned lands and to sell sites for development in accordance with its masterplan. However, consent authority for development remained with local government until 1997 when, following contentious debate over the development of a major site, State Government Minister for Urban Affairs and Planning resumed consent authority over the site by putting in place a Honeysuckle Regional Environment Plan which overruled local DCPs.
} 
followed by a series of short presentations from planners, service providers, and business and community sector representatives, raising issues and framing problems from a variety of perspectives. Participants were then broken up into small groups to examine a series of commonly accepted key issues. A planner was designated to each group so that collectively they could keep track of deliberations. Within the groups, participants were free to discuss whatever concerns they wished. As one planner put it, the approach was one of 'open slather...Anything you wanted you could get it out on the table (P3). ${ }^{3}$ After a period of group discussion, a facilitator co-ordinated the groups' reporting back and mediated broader collective discussion. All issues raised were recorded, debated and prioritised by the groups.

Planners were optimistic about the workshop outcomes. While there had been some adversarial debate, there was also broad endorsement of key strategies such as formulating separate DCPs to accommodate the differing characters of the city's east and west ends. However, no consensus was reached on the specifics of development densities and urban design controls as participants argued they needed more technical information to help them envisage various development options. Nonetheless, planners were confident that a consensual direction had been achieved with sufficiently broad levels of 'sign-off' on general strategies to enable them to proceed towards generating more specific development objectives and criteria.

\section{Stage 2: Translating deliberation into 'planning matters' (3rd)}

Following a long day of debate and deliberation by stakeholders (the workshop ran from 8.30am to 8pm), the second day consisted of a 'technical workshop' in which the previous day's deliberations were further discussed by a technical working group of planners with varied specialisms, services providers and representatives from state government and HDC. The purpose of this day was 'to try and crystallise and further that work while it was hot in everyone’s minds' (P4). A profusion of public concerns, interests, ideas, desires and needs

\footnotetext{
${ }^{3}$ The case study analysis draws primarily on practitioner reflection (Forester, 1998), along with the reflections of various participants in the participatory process including councillors, commercial interests, and community representatives. Interviewees are coded as follows: B, representative of business interest; C, councillor; $\mathrm{H}$, representative of HDC; $\mathrm{P}$, planning analyst; $\mathrm{R}$, representative of community interest. It should be noted that the term 'planner' is used to refer to planning officials with local or state government departments. In some cases the officials were professionally trained in disciplines other than formal planning (e.g. architecture) but all were working substantively in planning work within planning departments.
} 
had been raised which could not be neatly categorised into 'formal planning' and 'other' matters. The technical group's task was to translate these concerns into planning priorities, desired outcomes and action proposals, and to categorise 'non-planning' matters to be dealt with by relevant authorities. They also produced specific criteria on which DCP40 might be based. In Healey’s terms (1997, page 231) the translation process represented a significant separation of the process of deliberation from the formulation of policy directions. Though the first workshop provided diverse raw material, the technical group articulated the policy discourse that would frame the DCP thereafter. This discourse positioned the issues, terms, and organising concepts around which subsequent debate would focus (SEE TABLE 1).

INSERT TABLE 1 APPROX. HERE

The outcomes of the technical group's translation process were circulated to participants prior to a second shorter workshop that was intended to confirm stakeholders' support for the strategies thus far developed. This workshop also began with a series of presentations outlining the criteria that might be used to drive these strategies. A consultant provided the technical information participants felt they lacked in the first workshop. Short discussion periods were allotted for small groups to debate and comment on the circulated material. A facilitator was again used to co-ordinate collective discussion. In a process very similar to that described by Tewdwr-Jones and Thomas (1998), the format of discussion in the second workshop was more orthodox than in the first. The agenda was set largely by the specific contents of the circulated documents. One source of pressure on planners was the need to obtain stakeholder 'sign-off' on criteria that would enable them to proceed with drafting DCP40. Issues of a qualitative and aspirational nature that could not be addressed within a DCP were classed as 'non-planning' issues and earmarked for attention from other relevant authorities. Significantly, the holistic approach of the first workshop was lost and detailed discussion of the DCP's criteria began to dominate. In general, discussion became more critical as some participants became overwhelmed by the amount of material to be dealt with in the three-hour workshop and began to reject the process.

A prior history of acrimonious debate between specific interest groups began to resurface. Broadly speaking, the HDC and development interests were in favour of maximising development densities in DCP40 to take advantage of waterfront development opportunities. Though reaction from residents’ groups was mixed, they generally favoured lower densities, 
particularly on absolute waterfront. So, little was achieved in advancing mutual understanding or forging consensus as oppositional politics emerged and groups veered towards defending interest positions and rebutting alternative views. Planners themselves felt that they had tried to achieve too much, resulting in a loss of public trust and support and some disillusionment among both themselves and stakeholders. The workshop ended with planners reasserting their inclusive stance and undertaking to generate the DCP in line with the consensual directions and strategies elicited in the first workshop.

Stage 3: Policy outcomes $\left(3^{\text {rd }}\right)$

From this point onwards, the participatory process resembled a more traditional format. Having put the major principles in place, the detail of the draft plan was completed by urban design consultants. Council's social and environmental planning officers worked on the draft and included feedback from commissioned economic and social analyses of the likely impact of low-, medium- or high-density development options in the City West area. These analyses clearly favoured the medium-density option on urban design grounds. The draft DCP was released for display and planners followed an unprecedentedly widespread communication strategy aimed at eliciting broad public input. Only thirty-six written submissions were received, ranging from single page letters about specific aspects to comprehensive commissioned assessments of the DCP. Most, however, focused on development density and tended to reassert the positions stated in the second workshop. This issue was politically contentious enough to ensure that a negotiated consensual outcome was unlikely. Planners made a series of adjustments to the draft plan based on consideration of submissions, though their reaction was, of necessity, guided by the now established parameters of the DCP.

Ultimately, nine months after the first workshop, the DCP endorsed a medium-density development option as was recommended by the commissioned analyses of the development impacts of each option. Opinion on the outcome among residents' groups, commercial interests and councillors was divided. Most of the property and development interests, including the HDC, would have preferred a higher density but appreciated the certainty of the outcome. Resident group opinion was divided with some in favour and some resolutely opposed. Notably, the level of endorsement of the participatory approach to plan formulation tended to vary with participants' views on the DCP outcomes. In the later stages of plan formulation the participatory process reverted to a conventional format, albeit one that 
involved a wider range of participants than has traditionally been the case.

\section{Creating a 'shared-power-world': communicative planning theory and power relations} $\left(1^{\text {st }}\right)$

The first issue in question concerns the extent to which a 'shared-power-world' (Bryson and Crosby, 1992) can be created in which communicative rationality might emerge in the midst of the practical politics of planning practice. Just as critics of Habermas have implied (Fermia, 1997; Hillier, 2000), this case study suggests that actors cannot be expected to adopt the dialogic practices of listening and giving respect to all voices and value systems, nor to abandon political strategising in favour of formulating generalised interests. Actors in the case study did not cease to exercise power on entering deliberative forums: rather the political context in which communicative planning was set was carried into the argumentation process. Strategic action, which actors are unequally equipped to perform, persisted and particular instrumental rather than generalised interests dominated the discourse through which the development plan was formulated. It is argued here, therefore, that CPT does not adequately engage with the politics- and power-laden interests that infiltrate planning practice. How the 'soft infrastructure' of CPP might transform persistent entrenched interests, politically motivated strategic action and relations of domination that endure in planning practice remains unclear.

The first workshop in Newcastle was envisaged by planners as a deliberative forum in which they had attempted to minimise the distortions produced by power inequities:

[we were] very much involved in facilitating the people who were there, bringing up issues about each other's perspectives and working through those and trying to reach points of agreement...we have been using [the workshops] as a way of empowering groups in learning about how planning works and the tradeoffs involved.... It empowers them to then make some much more informed decisions about which option they are going to back. (P4)

We were trying to avoid that kind of scenario happening where it is who shouts the loudest or who has got the most political power that gets things on the board...somehow that workshop has got to be developed [where] people are going to feel safe enough that if they say something they are not going to be made to look silly and those points are going to be noted and respected and followed through on. (P2)

Planners mediated the process, clarifying claims, encouraging collaboration and creating an environment in which all claims for attention were to be heard, respected and valued.

But the participatory process could not be detached from the institutional and political legacies which constituted the boundaries of deliberation and shaped existing interactions and 
capacities. These legacies also forged a series of interest alignments which were framed within economic imperatives and political objectives and within a history of negotiations, achievements and defeats. These interests were unlikely to abandon their concerns and enter a deliberative forum without some notion of preferred outcomes. Rather, even as interests engaged in communicative action, they were likely simultaneously to engage strategically in teleological action, that is, to pursue appropriate means to achieve specific desired objectives (Tewdwr-Jones and Allmendinger, 1998). As one councillor put it:

This process crystallised a political fight that had been happening in the City for many years...between the residents' groups and the environment movement on one side and the developers on the other...And so there was a consciousness of this as a political process, as a negotiation process. (C3)

The prior history of engagement between these interest alignments had also produced a style of communicative routines, born of a local political culture and largely based on adversarial politics, which would not be overcome by the effort to produce deliberative rather than confrontational interactions:

A lot of them had never been on that sort of committee before. And they thought if you just yelled you would get your own way. Or repeated it sufficient times, you would get your own way. (R1)

Thus, some participants had 'misgivings' (R2) about entering the process and about what they felt it was likely to achieve, and planners were highly conscious of the difficulties of generating trust between participants.

The strategic economic and political context is one of power, which cannot be bracketed or comparmentalised (Phelps and Tewdwr-Jones, 2000). It presented planners with the dilemma of democratically realigning a planning instrument while managing persistent demands for higher density development, particularly on HDC development sites which were about to be marketed. State government had previously indicated that it was prepared to overrule local planning controls to achieve HDC development outcomes. Thus planners' entry into the process was conditioned by a priority of securing broad agreement to increasing development density in City West. In other words, within a framework of CPP, planners role was one of strategically-oriented guidance:

there was a certain understanding about how we might proceed with the DCP at a technical, professional level... and we scoped that with the community at those workshops... we needed to radically think about how the city needed to develop and to be structured and it really was a paradigm shift in thinking about the new and the old and what were the opportunities in the new area and ...perhaps challenging some the mindsets in Newcastle. There was a need for there to be a broader community 
understanding of that for us to go forward...there was a need for somebody to provide a direction and we did that up front. (P5)

Within the first workshop, planners employed a series of tactics aimed at securing broad agreement on priority issues, avoiding contentious issues on which consensus was unlikely to emerge, and creating opportunities for participants to move beyond established, adversarial group interests:

Well, at the major workshop there was a definite breaking of groups into smaller groups to focus on particular issues...in my mind there was an obvious intelligence about that...to ensure that those groups could be as effective as possible. To bring back some positive direction overall... I think there was a bit of thinking about how particular groups would work as a team, or indeed how perhaps strong personalities should be put together in one group so that they could work through some of the stronger issues that they have and that neither would dominate a particular group's view. (P5)

These steps and actions represent a strategic attempt to transform the discourse of policymaking (see Hajer, 1993), to re-frame the problem of inner city development in a new storyline. This attempt rests on teleological action existing simultaneously with communicative action and being capable of actively channeling its direction.

Strategic and teleological action were common too amongst residents' groups and business interests, whose aspirations and concerns were varied. Some residents' groups focused their attention strategically on opposing the proposed increase in development density. Property and development interests had the explicit agenda of seeing higher densities written into the DCP. For instance, the HDC's strategic interest in increased density and development certainty was derived from its structural position as a Development Corporation with a brief to create profitable development sites:

Our aspirations were to get certainty for investors. We don't want the debates to happen after we have issued the land... Because they can't afford to get tied up for eighteen months if they have invested. And we can't afford to have that. (H1) Planners also highlighted how participants valued the strategic outcomes of deliberation above the opportunity for communcatively developing consensual policy settings:

So there were people who were dissatisfied that the outcomes didn't go their way. And I believe they will not see that there was any participation because their participation wasn't heard from their point of view... It all comes down to 'did I get my way or not?' (P1)

Clearly then, alignments, attachments and obligations were not abandoned on entering deliberation. Rather, they were woven into the practical operation and reasoning processes of deliberation. Rather than being oriented solely towards the dialogic, consensual practices of communicative action, all the actors in the participatory process appear to have been equally 
oriented towards the 'distortions' of purposive and strategic action aimed at achieving objectives arising from locally-situated and overlapping social relations, structural positions, and cultural systems of valuing and meaning.

Teleological action also extended beyond the communicative action of deliberation, 'going round the back' of the formal participatory process (Hillier, 2000). Rather than abandoning strategic aims unlikely to be agreed to argumentatively, actors appealed to informal sources of legitimisation for their objectives (Tewdwr-Jones and Allmendinger, 1998). Groups from divergent discourse communities, though with similar objectives, forged unexpected strategic links and collaborated in their submissions on the draft. ${ }^{4}$ All actors exploited available social relations, business networks and capacities to lobby local politicians, state and local government planners, and the media. These networks and access to them are variously rich and thus the capacity to benefit from them strategically is unevenly distributed, reflecting the distributions of other power sources (Hillier, 2000). Pluralist interest group politics, strategic action and bargaining processes, though they may have been clothed in appeals to a deliberative process, persisted throughout every stage of the process. Existing class interests, political allegiances and parochial concerns were sustained (see Bernstein 1992: Fermia, 1997; Tewdwr-Jones and Allmendinger, 1998). It was a situation in which not all participants were interested in building new relations of power, and may have valued legitimising their claims above developing trust, building appreciation of new knowledges or generating new systems of meaning and valuing (see Gambetta, 1998).

While actors may have been willing to debate the means through which they might pursue their interests, the process did not significantly transform the interests they held. The necessary moment of power-neutrality, during which specific interest claims could be surpassed and a mutual appreciation of divergent understandings and knowledge forms developed, was not created. Without this 'frame-shifting' transformation (Rein and Schon, 1993) the potential for a new discourse of generalised, consensual interests to emerge is limited. Clearly then, this participatory process was not one in which the 'distortions' of strategic action and power from other settings were removed and in which communicative rationality could overcome an enduring instrumental rationality. Despite the attempt to create a power-neutral deliberative forum, participants continued to be embedded in a web of

\footnotetext{
${ }^{4}$ E.g. one residents' groups who opposed waterfront development and favoured low densities collaborated with a developer whose development site was likely to lose value in a high density development scenario.
} 
inequalities concerning material and discursive power, and value hierarchy. The process reflected a context constituted in power that inflected action, debate and reaction.

This analysis suggests that it cannot be assumed that that participants will behave openly, collaboratively and with integrity while being faced by interest-alignments they perceive as conflicting with their own (Allmendinger, 1999; Friedmann, 1998). Discourse in such situations is unlikely to be led soley by the 'rational critique' of communicative rationality (Forester, 1999b). Instead it is likely to involve rationalisation, strategising and the deployment of tactics and persuasive discourse in support of established positions (MacRae, 1993; and see Flyvbjerg, 1998a). The social actions necessary for the development of intersubjectively-formed communicative rationality cannot operate in isolation from a range of strategically- and instrumentally-oriented social actions which infiltrate them (see Phelps and Tewdwr-Jones, 2000). In this instance, pluralist politics, specific-interests and strategic action co-existed with collaborative politics, generalised interests and communicative action. Such actions can be only artificially comparmentalised.

This assertion goes to the heart of the first critique of this paper, that CPT fails to deal with the situatedness of planning practice because it abstracts 'doing' planning from contextual understanding. While acknowledging the complexities of the social and discursive constitution of power relations, CPT then brackets the problem of power asymmetries that are expressed in entrenched interest, strategic action and relations of domination. This bracketing can only be maintained by abstracting from the realities of context (Huxley and Yiftachel, 2000) which involves a failure to countenance power (Flyvbjerg, 1998a). Thus the use of teleological action in pursuit of specific interests is treated as a deviation to be controlled rather than as an integral component of situated planning practice.

\section{Communicative planning theory, the role of planners and the nexus of power, rationality and knowledge $\left(1^{\text {st }}\right)$}

The second issue in question concerns the difficulties of asserting alternative forms of knowledge and rationality above the hegemonic knowledge and rationality forms which frame planning practice. The complex relations between knowledge, rationality and power renders them analytically inseparable (Flyvbjerg, 1998b). In Foucauldian terms, knowledge is a discourse built through particular systems of rationality. Power takes effect through the ability to define what is accepted as knowledge, and is accorded the 
authoritative status of truth. The production of knowledge is therefore an effect of the exercise of power (Gordon 1980; Cousins and Hussain, 1984). Together, power, knowledge and rationality constitute a nexus in which power relations are effected through a rationality which drives the social production of knowledge. Thus in planning practice, the effects of power are carried through the discourses, strategies and techniques which arise from and reinforce dominant knowledge/rationality forms (see Cousins and Hussain, 1984). Using the notion of a nexus of power, knowledge and rationality, it is argued here that CPT does not acknowledge sufficiently the variations in discursive power between actors whose knowledge/rationality forms are already validated and those actors whose knowledge/rationality forms are discursively disempowered (see Burgess and Harrison, 1998). This represents another dimension of the failure to countenance power in CPT.

CPT attends closely to the hegemonic position of instrumental rationality and technoscientific knowledge forms which are embedded in institutionalised planning systems of understanding, valuing and practice. The theory deals particularly with how these forms carry and exercise power (Flyvbjerg, 1998b).They determine how planning issues are framed, which forms of knowledge and modes of argument are valorised, and which forms of action are likely to emerge (Innes, 1998). Yet in ascribing a role for planners, CPT abstracts them from the web of connections between knowledge/rationality forms and power which frame planning practice (Huxley and Yiftachel, 2000, page 12). Instead, planners are presented as 'critical friends' whose role is to mediate deliberation so as to reveal the relations of knowledge, rationality and power which frame claims for attention. They manage and filter public deliberation. They, above all participants, are charged with rational assessment and critique, and of merging stakeholders' collective desires with institutional, administrative/legal and resource frameworks to fashion policy discourse (Jennings, 1993). As Huxley (2000, page 14) ironically observes, CPT deems planners to be 'blessed with unusual insight and reflexivity', capable of reflecting on their own framing in a web of knowledge, rationality and power as well as exploring those of others. However, if planning practice is contextualised in its institutional, administrative/legal and discursive framing, planners' role as critical friend is both compromised and problematised.

\section{Power/knowledge/rationality and sorting through the 'argumentative jumble' $\left(2^{\text {nd }}\right)$}


To produce a coherent planning instrument or policy, planners are required to sort through and prioritise an 'argumentative jumble' of participatory input founded on varied systems of knowledge, value and meaning (Healey, 1997, page 276). Sorting and prioritising are knowledge producing practices which, of necessity, reflect power relations (Gordon 1980). Through these practices, certain knowledge claims will be accepted and given authoritative status through their installation within the mechanism of the DCP. Planners' knowledge/rationality systems are deeply engaged in this sorting process. The process of sorting also involves translating, interpreting, even manipulating the needs, desires and values emerging from moral and aesthetic forms of reasoning/knowing so that they might 'fit' a planning instrument more suited to accommodating needs and demands assessed through the analytical routines of logical deduction and empirical inquiry. Translation unavoidably engages with the power/knowledge systems of instrumental rationality which still dominate planning practice (Huxley, 2000).

In the Newcastle example, the process of sorting and translation foregrounds the tensions between planning's power/knowledge/rationality systems, accustomed to techno-scientific analysis and expert modes of reasoning, and the varied systems of knowledge/rationality introduced through inclusionary participation. In formulating DCP40, planners commenced from an inclusionary ethic aimed at enabling the development of a deliberative consensus. The background paper used to initiate the participatory process established the scene for the policy terrain. The 'scene-setting' phase of any participatory process presents a 'storyline' with an organising potential (Kaplan, 1993; Innes and Booher, 1999). Here it provided a basis of 'facts and data' (H1); an economic and demographic analysis presented in the measured language of scientific evidence suggesting straightforward cause-effect relations in Newcastle's development dilemma. Presentations followed which incorporated communitybased expertise, knowledge and priorities into the 'scene-setting'. These presentations included statements of belief and value about the qualities of place that the DCP should aspire to create.

Planners attempted to create inclusionary communicative routines that could nurture the varied communicative styles and value systems of divergent cultural communities. Participants applied a hierarchy of value to modes of argument and expression employed in argumentation. Business interests tended to dismiss contributions that they categorised as 'not well informed' (H1), or not 'proper focused and objective input' (B3), based on 'emotion 
rather than factual resource material backing' (B1). Likewise they dismissed contributions that had been delivered in 'chanting mode’ by ‘decibel democrats' (B1). Planners' response was to attempt to counter this:

One thing that [is difficult to explain] to the business community is that there is a value system attached to the opinion of the community groups and that actually has great merit. And that is the message you have to get back across - [that] there is merit in someone else's opinion. (P1)

They also practised an advocacy role, seizing on issues raised by participants that seemed likely to be glossed over in the pressure from commercial interests to secure high development densities and to assert standards of argumentation and expression aligned with instrumental rationality:

I found myself taking on an advocacy role and promoting some of the stuff that I felt was dropping off the agenda... taking that commitment from the [white] board and saying that it is really important to put this in... It was interesting how much you had to keep hammering that because the other pushes were also very strong. (P2) Undoubtedly genuine efforts were being made to encourage social collaboration, to build relationships and nurture deliberation. Nonetheless, planners' actions to 'resist some forms of power as they exercise others' (Forester, 1999a, page 5) were shaped by their position in a power/knowledge/rationality nexus broadly based on instrumental rationality and its faith in professional, expert knowledge forms. Planners' management of the plan formulation process involved techniques of discursively framing problems and formulating strategic responses which emplotted the outcomes of deliberation into a frame of instrumental rationality and its attendant knowledge forms.

Planners operate within a 'hard infrastructure' of legal/administrative and institutional procedures, guidelines and rules that are products of instrumental rationality and techniques for creating its knowledge forms. The DCP's regulatory function within the land use governance system determined the issues and material demands to which it could practically respond, being limited to statutory techniques of development control. This created discursive boundaries around which forms of value/belief and systems of reasoning/meaning could easily be captured within the DCP. Planners' understanding and knowledge of the 'hard infrastructure' infused how they performed in shaping attention, providing information, clarifying distorting 'misinformation', alternatively challenging and championing assertions (Hillier, 1993). In this performance, they saw themselves as practising pragmatic 'realitychecking' (P4), itself a technique of instrumental rationality. This involved selecting when they inserted information about resources, constraints, and institutional limits: 
There was a conscious effort, I suppose, in deciding what information we would be providing to the community workshop at particular times. Often we had an understanding, I think, about how we saw the thing could evolve and develop. But it was a conscious effort not to pre-empt a community understanding of solutions because we had a technical expertise that they necessarily didn't have. So there was a conscious effort to drip it out slowly, evolve.... (P5)

Planners' vision of how 'the thing could evolve and develop' was already conditioned by their expert knowledge of the implications for the DCP and its institutional and political settings of discourses being generated by participants (Inner, 1998). Their 'technical expertise' framed how and when they introduced into the process information on limits, constraints and possible policy solutions. This constituted 'reality-checking' on the directions in which unrestrained deliberation might have developed.

Planners' orientation to the legal and policy constraints of the policy terrain militated against translating some community discourses into plan development (Tewdwr-Jones and Thomas, 1998). Initially, workshop participants' widely varying input was summarised into a core concept-usually to a point or statement recorded on a white board — which was interpreted as a 'mandate' (P1) from which the technical working group could proceed. Through this representational strategy, complex expressions of value and desire were condensed and filtered through the prism of spatial planning analysis with its interpretive predilections intact (see Tewdwr-Jones and Thomas, 1998). As one commercial actor put it, the technical working group ensured that public input 'came down to propositions that translated into proper things’ (H1).

There was some acknowledgement amongst planners of the filtering effect of translation on knowledge/reasoning forms that did not sit comfortably within a professional/expert knowledge frame, revealing the disciplinary power of the practice of translation:

there were probably some sacrifices of that local knowledge that were based on expert opinion saying "well look, we acknowledge the value of that opinion, however we don't believe it outweighs what we believe is the greater good”. (P1)

One residents' group representative articulated the sense that translating the outcomes of argumentation into criteria with technical planning functionality, leached out their value and meaning:

[they] worked on an extra day to formalise the workshop-a lot of key issues for me seemed to get 'lost' in the process... [local knowledge and community priorities] were patronised and listed etc. but in the final outcome they had either disappeared or been trivialised. (R2)

Certainly, translating participants' input into criteria and objectives oriented towards the 
specifics of a DCP had the effect of narrowing and focusing the discourse that would occur in all stages after the first workshop. Community priorities and aspirations about the 'intangible' experiential qualities of place could only work within the DCP if they could be translated into elements attainable through its techniques. One planner summarised the disciplining effect that this had on which desires and values could become authorised through the DCP:

(W)e took the fine-tuned elements and incorporated those in the philosophy of the DCP where appropriate. Because there were a lot of things that happened in that forum that were not appropriate to a DCP... A lot of them were really intangible and you couldn't put them in a DCP... so I believe we have translated a lot of it but a lot of it we are still working with... I think the hardest point is trying to take the esoteric and trying to build it into a workable document.... (P1)

The dynamic, multiple and multifaceted nature of claims asserted in deliberative forums (Howitt, 1994) are not easily housed within the linear, compartmentalised logic which underpins institutionalised planning practice and its predominant discourse of expert knowledge. Planners' knowledge-frames and the accompanying analytical and administrative techniques supplied a rationalising structure in which certain values and concerns about community life were displaced and the scope of acceptable discourses narrowed around the elements of the DCP.

In sorting through the public submissions on the draft DCP, this rationalising structure was engaged again in the 'technical assessment' employed to select those submissions which justified alteration of the DCP, were rejected on the basis of 'sound planning principles' (P4) or were judged too 'intangible' (P1) to be accommodated. The sorting process was also disciplined by public submission comments from professional planning associations and commercial interests. They argued for the exclusion from the DCP of issues arising from value/reasoning systems different to those of technical and economic rationality on the grounds that they raised 'philosophical' and 'social' issues which should be separated from the 'priority technical issues' of land use regulation and development control. Ultimately, unlike in the draft, the issues of social and environmental planning to which these comments allude were removed from the development guidelines and control section of the DCP. Instead they were disassociated from statutory mechanisms of development control and included in a short, more aspirational section towards the end of the document.

Each phase of sorting through the 'argumentative jungle' involved practices of translation and interpretation in which planners' drew on their value-infused professional expert knowledge/rationality frames and applied them through the techniques of 'technical 
assessment' and 'reality-checking'. There is a power-relation in operation here which threatens the assertion of alternative knowledge/rationality forms and renders planners' role as 'critical friends' extremely problematic.

The appeal to (and of) expertise $\left(3^{\text {rd }}\right.$ )

Examining how and under what conditions planners appeal to professional/expert

knowledge/reasoning forms further illustrates the fragility of alternative knowledge/reasoning forms, even under conditions explicitly aiming at their inclusion. In the Newcastle example, planners' practical operation was one of conflict avoidance driven by the pressure to produce a DCP and an acceptance that the notion of generating consensual aspirations for the DCP was implausible. Politics and pragmatism meant that conflict, often arising between differing systems valuing and producing meaning, was managed by removing issues from the deliberative process to be 'managed internally... on a technical professional level' (P4):

... we were actually doing the problem solving ourselves... So we were providing the opportunity for people to say what they thought were the major problems are and what they thought the strategies could be, but all that information was coming back to us and then we were going about it.... the broader agenda was that there had to be some level of agreement and signoff by all parties. (P2).

This produced a process of political management where value/reasoning differences were redefined as problems to be solved professionally through analysis and deduction of a logical solution based on expert planning principles (see Flyvbjerg, 1998b). This redefinition witnessed an assertion of the established validity of expert knowledge/reasoning and a removal from the realm of emotion, value, and passion that underlie moral and aesthetic forms of reasoning. By reclassifying conflicts for professional solution, legitimacy to could be claimed on the grounds of 'sound planning practice' aiming at producing a 'reasonable outcome’ (P5).

In particular, the politics of conflict (especially regarding specifications for waterfront development) were handled through the mechanism of professional assessment, both in working up the draft DCP and in having its 'feasibility' verified and its legitimacy confirmed according to professional analytical standards. Appeals to the rationality of technicallydeduced 'sound planning principles'(P4) continued as conflicting public submissions on the draft's exhibition were assessed by the planners:

So it's the balancing of it based on ..., ok you have got two different points of view, "what information have you already got, I suppose, that supports one or the other..." You 
go back to the Urban Design Advisory people and we say well these people want this and these people want this, we believe this is the case, what is your feedback on that. You go back to your economic advisers on the viability point of view.. "If we do this and do this how do the numbers stack up"? So there is a lot of to-ing and fro-ing between the professionals in deciding which way we wanted to go with the feedback we got out of the participation process. (P3)

Of course planners' appeals to the rationale of professional expert knowledge were also shaped by political and institutional contingency and employed as a persuasive form of argument (see Flyvbjerg, 1998b). Appeal to independent professional expertise and criteriabased scientific analysis was exploited as planners' strived to resist pressure to allow the highdensity development option:

(Developers) said “we need a higher density of development”. They were very up front and very forthright about that...And going through the process [the consultants] were saying "no way pal. You can't do that to that area. It is not right"... There was a push by them but I would say that it was managed very well by consultants who said look ... it is just not going to work. (P3)

Pressure from community groups and development interests respectively meant that avoiding both the low- and high-density development options would be politically necessary. The discourse of 'sound planning judgement', an appeal to expert knowledge, could be employed in a highly contested context, as a means of negotiating and legitimising the outcomes of the DCP in a politically contingent manner. The source of conflict could be removed from its social context and technically framed (Fischer, 1993).

Both the process of translation and the appeal to expert knowledge in formulating the DCP illustrate planners' positioning in a power/knowledge/rationality nexus and their appeal to institutionalised cultural patterns of interpretation and evaluation (see Fraser, 1997). Power is inseparable from knowledge forms, their founding rationalities and their claims to truth (Flyvbjerg, 1998b). Before knowledge claims are accepted, they have to be acknowledged, respected and, ultimately, validated (Code, 1991). In the institutional context of planning, planners' authority is based on pre-existing validation of their knowledge and expertise. CPT highlights how, in the name of dispassionate expert planning decision-making procedures, other knowledge forms - experiential, local, intuitive, tacit, moral and expressive - are discounted as being of lesser validity. The theory proposes alternative planning practices in which the conditions are created for these knowledges to be validated and for a communicative rationality to emerge which might supplant the dominance of instrumental rationality. But in so proposing, CPT abstracts planners from their position in a power/knowledge/rationality nexus without accounting for its imbrication both in plannings’ 
dominant knowledge hierarchy and in its institutional framing. It relies on planners' goodwill and reflexivity to drive a new knowledge discourse founded in communicative rationality. Such reflexivity is a weak defence in the face of the disciplinary power of planning's dominant knowledge discourses.

Situated observation and analysis of planning practice illustrate the endurance of discursive power imbalances between already validated power/knowledge/rationality forms whose authoritative status renders them less vulnerable to challenge (Collins, 1999) and those forms whose validity struggles for recognition. The participatory process could not simply be isolated from the planners' framing in techniques and discourses founded in instrumental rationality and carried through knowledge practices through which power is exercised. The knowledge-producing practices, strategies and techniques of expert planning represent the exercise of power/knowledge built around a system of instrumental rationality. Even as planning analysts were committed to an inclusionary ethic, giving voice to a broad range of

voices with divergent frames valuing and reasoning, the communicative styles of instrumental rationality were asserted with relative ease (Burgess and Harrison, 1998).

Planners might well be aware of the limitations this places on incorporating other knowledge forms into the discourse and giving them authoritative staus. Indeed they may well retreat to professional judgement and technocentric value-sets to insulate themselves from the complexity with which they deal with and the non-negotiable nature of interests (Allmendinger, 1999; Murtagh, 1999). Nonetheless, their knowledge/rationality is valorised in the institutional and legislative/administrative forms which frame practice, giving it a persistent legitimacy and authority over moral or aesthetic knowledge/rationality forms. Thus, there is an ongoing tension between planners' embeddedness in power/knowledge/rationality nexus and their capacity to act with the aim of empowerment claimed of CPP.

\section{Conclusion ( $\left.1^{\text {st }}\right)$}

The critiques presented here address CPT's commitment to a politics of consensus (Allmendinger, 1999; Huxley and Yiftachel, 2000) which suggests that reaching consensus is a matter of epistemological realignment so that power and difference can be set aside, temporarily at least. However, such a progression relies upon the possibility of subjects' stepping outside the cultural, social, political and economic power-grids in which they are constitued in order to reflect rationally, knowingly and communicatively upon them. 
According to this view, power, difference and inherent conflict around them are boundable and containable rather than constitutive and irreducible. Such a view denies that subjects, and indeed all social objects, are unavoidably constituted in power and difference rather than solely in rationality (Mouffe, 2000). Subjects are variously located in relations of domination which structure and are structured by overlapping social, economic, political and cultural power-grids, making power irreducible and antagonism inevitable. There is no possibility of retreat into an inter-subjective rationality that does not bring power, difference and conflict along with it. The case study presented here suggested that conflict persisted and communicative action could not be neatly removed from other forms of social action. It also suggested that the transparently reflexive reasoning processes of communicative rationality were unattainable. Power always framed the negotiations, interpretations and calculations at work. Any compartmentalisation of communicative rationality from acts of power and various other 'communicative distortions' is untenable.

Power and difference cannot be set aside, even temporarily, through epistemological realignment. The constitutive nature of power and difference is an ontological matter (Mouffe, 2000). It cannot be reasoned away. Nor can its conflicts be dissolved into a unifying consensus. On the contrary, urban life and urban politics themselves are shaped not by consensus but by conflict (Holston 1995: Amin and Graham, 1997). All 'consensual discourse' of necessity involves the exclusion of some voices and the foreclosure of certain possibilities (Haber, 1994). To suggest communicative rationality as the basis for judging which voices and possibilities should validly be excluded denies the constitutive nature of power and difference. CPT's abstraction from the context of power glosses over the political realities of what is likely to happen when relations of domination persist and infiltrate the 'soft infrastructure' of bottom-up participatory practices, and then converge with 'hard infrastructure' geared towards top-down governance practices. A theory of planning that does not adequately engage with power in its varied manifestations, expressions and effects may do little to disrupt the practices of the already powerful, and thus may retain and entrench relations of dominance and embedded power (Amin and Graham, 1997; Fermia, 1997; Fincher, 1998; Sunley, 1999). Indeed, by treating power, difference and their inherent antagonisms as removable through rational argumentation, CPP lends itself to allowing the unavoidable exclusions of its policy making processes to become institutionalised and its necessary forms of partiality to become systematised-the very opposite of the democratising 
impulses which drive CPT. Thus planning theory needs to be able to address the questions of how to proceed without consensus and in the face of conflict, and how to define the institutional conditions that are appropriate to such planning practice. There are multiple heterogeneous publics who are not necessarily well served by its politics of consensus (Young, 1990). In other words, planning theory needs to have conflict rather than consensus as its frame of reference (Flyvbjerg, 1998a).

An alternative theorisation of planning which replaces the core concept of rational consensus with the permanence of conflict, inequality and domination may resist bracketing power and its outcomes and engage more productively with planning's context of power (e.g. see Sandercock, 1998). While it is beyond the scope of this paper to investigate the form such theory might take, broad suggestions can be made drawing on Mouffe's (2000) agonistic model of democracy. It is clear that a more democratic planning theory and practice would need to embrace the conflictual dimensions of all planning decision-making. This suggests a radical politicisation of planning and a reorientation of planning theory from a normative to a political basis. This would involve recognition that planning decision-making of necessity involves partiality, compromise and some forms of exclusion in its attention to power relations and its treatment of difference. The key task thus becomes one of identifying where relations of domination are working through planning, and to imagine institutional conditions and planning practices which might limit those relations in politically legitimate ways. The aim becomes one of acknowledging the limits of consensus and ensuring that the outcomes of planning decisions do not result in the systematic exclusion of particular social identities or value systems. This will require both an orientation to conflict (see Mouffe, 1995) and a recognition of the politics of planning's practical operation—Flyvbjerg's (1998a) realrationalität.

In planning practice, procedures might be developed to institutionalise inclusive participation with multiple opportunities for 'ear, voice and respect'. These procedures might usefully target the many laudable aims of CPP_developing social, political and intellectual capital, challenging the culture and organisational routines of institutional settings, inserting diverse discourse communities into the dialogical practices of governance. The institutionalisation of such procedures would be a starting point for mobilising enabling power on the part of discourse communities that have been systematically marginalised from a decision-making practices. This would widen the scope of the value systems, forms of 
knowledge and meaning accepted as legitimate and could be used to inform the formulation of broad planning aims. But it is the application of these aims in specific and contingent instances of decision-making that will determine whether more or less democratic outcomes result (see Fraser, 1997).

Within planning dialogue, robust deliberation may enable the power relations and antagonisms at work in the compromises that must be reached in decision-making to be exposed and examined. Crucially, the purpose in these specific instances would not be to reconcile 'winners and losers' in compromise, nor to negate the existence of adversarial positions and value systems, for it would accept the constitutive nature of power and difference. Rather it would be to cease the search for consensus and to seek compromises that, while contingent and particular to each instance of decision-making, would be housed within democratic values and practice. This is the process of agonism. Thus an orientation to conflict in planning theory would not result in a practice concerned with eliminating the effects of power. This cannot be achieved. Such an orientation would be about reaching compromises which, as Mouffe suggests, "constitute forms of power more compatible with democratic values"(2000, page 100). Ultimately, planning theory oriented to conflict and to democratic compromise is likely to support more democratic planning practices and outcomes than an orientation to consensus.

\section{Acknowledgements}

Thanks are due to three anonymous referees and to the journal editors for their challenging and constructive comments. This paper was largely written while on sabbatical at the Department of Urban Studies, The University of Glasgow. Thanks are due to the Department and, in particular, to Mike Raco and Rowland Atkinson for their comments on a previous draft. 


\section{REFERENCES}

Allmendinger P, 1996, "Development control and the legitimacy of planning decisions. A comment" Town Planning Review 67 229-233

Allmendinger P, 1999, "Beyond collaborative planning", Paper presented to the XIII conference, Bergen, July

Amin A, Graham S, 1997, "The ordinary city" Transactions of the Institute of British Geographers 22 411-430

Arnstein S, 1969, "A ladder of citizen participation" Journal of the American Institute of Planners, 35, 45-54

Bernstein R, 1992, The New Constellation: The Ethical-Political Horizons of Modernity/Postmodernity (MIT Press, Cambridge, MA)

Burgess J, Harrison CM, 1998, "Environmental communication and the cultural politics of environmental citizenship" Environment and Planning A 30 1445-1460

Bryson J, Crosby B, 1992, Leadership for the Common Good: Tackling Public Problems in a Shared-Power World (Jossey-Bass, San Francisco)

Cabinet Office, 1998, Participation and the NSW Policy Process: A Discussion paper for the Cabinet Office of NSW (New South Wales State Government, Sydney)

Code L, 1991, What Can She Know? (Cornell University Press, Ithaca)

Collins C, 1999, "Applying Bakhtin in urban studies: the failure of community participation in the Ferguslie Park" Urban Studies 36 73-91

Cousin M, Hussain A, 1984, Michel Foucault (Macmillan Press, London)

Crofts D, 1998, "Place management" Australian Planner, 35, 49-53

Crofts D, 1999, Newcastle (Australia) sets a Pathway to Sustainability Manuscript available from the author, City Planning, Newcastle City Council, Newcastle, 2300

Davidoff P, 1965 "Advocacy and pluralism in planning" Journal of the American institute of Planning, 31, 331-338

Department of Urban Affairs and Planning, 1999, Plan Making in NSW: Opportunities for the Future-Discussion Paper (DUAP, Sydney)

Douglass M, Friedmann J, (Eds) 1998, Cities for Citizens (Wiley and Sons, Chicester) Dryzek J, 1990, Deliberative Democracy: Politics, Policy and Political Science (Cambridge University Press, Cambridge) 
Dryzek J, 1993, "Policy analysis and planning: from science to argument" in The Argumentative Turn in Policy Analysis and Planning Eds F Fischer, J Forester Eds (Duke University Press, Durham, NC) pp 213-233

Fermia F, 1997, "Complexity and deliberative democracy" Inquiry 39 359-397

Filion P, 1996, "Metropolitan planning objectives and implmentation constraints: planning in a post-fordist and postmodern age" Environment and Planning A 28 16371660

Fincher R, 1998, "Planning for cities of difference" in Renewing Australian Planning? New Challenges, New Agendas Eds B Gleeson, P Hanley (Research School of Social Sciences, Australian National University) pp 51-71

Fischer F, Forester J, (Eds) 1993, The Argumentative Turn in Policy Analysis and Planning (Duke University Press, Durham, NC)

Fischer F, 1993, "Policy discourse: the politics of Washington think-tanks" in The Argumentative Turn in Policy Analysis and Planning Eds F Fischer, J Forester Eds (Duke University Press, Durham, NC) pp 21-42

Forester J, 1993, "Learning from practice stories: the priority of practical judgement" in The Argumentative Turn in Policy Analysis and Planning Eds F Fischer, J Forester Eds (Duke University Press, Durham, NC) pp 186-209

Forester J, 1996, "Beyond dialogue to transformative learning: how deliberative rituals encourage political judgement in community planning processes" in Democratic Dialogues: Theories and Practices Ed S Esquith (University of Poznan, Poznan) Forester J, 1999a, "An instructive case study hampered by theoretical puzzles: critical comments on Bent Flyvbjerg's rationality and power", (http://www.crp.cornell.edu/forester/Bentcritical.htm)

Forester J, 1999b, "Reflections on the future understanding of planning practice" International Planning Studies 4 175-193

Flyvbjerg B, 1998a, "Empowering civil society: Habermas, Foucault and the question of conflict" in Cities for Citizens Eds M Douglass, J Friedmann (Wiley and Sons, Chicester) pp 185-211

Flyvbjerg B, 1998b Rational and Power: Democracy in Practice (University of Chicago Press, Chicago) 
Fraser N, 1997, "Social justice in the age of identiy politics: redistribution, recognition, and participation" Tanner Lectures on Human Values 19 3-67

Friedmann J, 1987, Planning in the Public Domain: From Knowledge to Action (Princeton University Press, NJ)

Friedmann J, 1998, "Planning theory revisited" European Planning Studies 6 245-53

Gambetta D, 1998, "“Claro!”: an essay on discursive machismo" in Deliberative Democracy Ed J Elster (Cambridge University Press, Cambridge) pp 19-43

Gibson K, Watson S, (Eds)1995, Postmodern Cities and Spaces (Blackwell, Oxford)

Goodman R, 1972 After the Planners (Penguin, London)

Gordon C, 1980, Power/Knowledge (Harvester Press, Brighton)

Haber N, 1994, Beyond Postmodern Politics: Lyotard, Rorty, Foucault (Routledge, New York)

Habermas J, 1984, The Theory of Communicative Action: Volume 1: Reason and the Rationalisation of Society (Polity Press, Cambridge)

Habermas J, 1996 The Habermas Reader, Ed W Outhwaite (Polity Press, Cambridge) Hajer M, 1993, Discourse coalitions and the institutionalization of practice: the case of acid rain in Great Britain in The Argumentative Turn in Policy Analysis and Planning Eds F Fischer, J Forester (Duke University Press, Durham, NC) pp 43-77

Healey P, 1992, "A planner's day: knowledge and action in communicative practice" Journal of the American Planning Association 58 9-20.

Healey P, 1993 "Planning through debate: the communicative turn in planning theory" in The Argumentative Turn in Policy Analysis and Planning Eds F Fischer, J Forester (Duke University Press, Durham, NC) pp 233-53

Healey P, 1997, Collaborating Planning: Shaping Places in Fragmented Societies (Macmillan Press, London)

Healey P, 1998a "Building institutional capacity through collaborative approaches to urban planning" Environment and Planning A 30 1531-1546

Healey P, 1998b, "Collaborative planning in a stakeholder society" Town Planning Review 69 1-21

Healey P, Hillier J, 1996, "Communicative micropolitics; a story of claims and discourses" International Planning Studies 2 165-184 
Hillier J, 1993, "To boldy go where no planners have ever..." Environment and Planning

D 11 89-113

Hillier J, 1998, "Epistemological diversity and its implications for new research programs in Australian urban studies" Paper presented to Workshop on Diverstiy and regulation in Australian cities, University of Melbourne, 6-7 August, 1998

Hillier J, 2000, "Going round the back? Complex and informal action in local planning processes" Environment and Planning C 32 33-54

Hirst P, Associative Democracy:New Forms of Economic and Social Government (Polity Press, Cambridge)

Hoch C, 1994, What Planners Do (American Planners Association Press, Chicago)

Holston J, 1995 "Spaces of insurgent citizenship" in Making the Invisible Visible: New

Historiographies for Planning Ed L Sandercock (Franco Angeli, Milan) pp 35-52

Hoppe F, 1993 "Political judgement and the policy cycle: the case of ethnicity policy arguments in the Netherlands" in The Argumentative Turn in Policy Analysis and Planning Eds F Fischer. J Forester (Duke University Press, Durham, NC) pp 77-101

Howitt R, 1994, "SIA, sustainability and the narratives of resource reasoning: Aboriginal interventions in impact stories" Unpublished paper, School of Earth Sciences, Macquarie University, Sydney

Huxley M, 2000, "The limits to communicative planning” Journal of Planning Education and Research 19 369-77

Huxley M, Yiftachel O, 2000,"New paradigm or Old Myopia? Unsettling the communicative turn in planning theory" Journal of Planning Education and Research $19333-42$

Innes J, 1995, "Planning theory’s emerging paradigm: communicative action and interactive practice" Journal of Planning Education and Research 14 183-91

Innes J, 1998, "Information in communicative planning" Journal of the American Association of Planners 64 52-63

Innes J, Booher D, 1998, "Consensus building as role playing and bricolage: toward a theory of collaborative planning" Journal of the American Association of Planners 65 92-96 
Jennings B, 1993, "Counsel and consensus: norms of argument in health policy" in The

Argumentative Turn in Policy Analysis and Planning Eds F Fischer. J Forester (Duke University Press, Durham, NC) pp 101-117

Kaplan T, 1993, "Reading policy narratives: beginnings, middles and ends" in The Argumentative Turn in Policy Analysis and Planning Eds F Fischer. J Forester (Duke University Press, Durham, NC) pp 167-186

MacRae D, 1993, "Guidelines for policy discourse: consensusal versus adversarial” in The Argumentative Turn in Policy Analysis and Planning Eds F Fischer, J Forester (Duke University Press, Durham, NC) pp 291-319

Mandelbaum S, 1991, "Telling stories" Journal of Planning Education and Research 10 79-99

Martin P, Halpin D, 1999, "Local governance of Australian rural environments: the development and performance of discursive institutions" Paper presented to the 95th annual meeting of the Association of American Geographers, 24-27th March, Honolulu, Hawaii

$\mathrm{M}^{ } \mathrm{G}$ Guirk PM, Winchester HPM and Dunn KM, 1998, “On losing the local in responding to urban decline" in The Entrepreneurial City: Geographies of Politics, Regime and Representation Eds T Hall, P Hubbard (John Wiley, London) pp 197-128

Moore-Milroy B, 1991, “Into postmodern weightlessness” Journal of Planning Education and Research 10 181-187

Mouffe C, 1995 "Post-Marxism: democracy and identity" Environment and Planning D 13 259-67

Mouffe C, 2000 The Democratic Paradox (Verso, London)

Murtagh B, 1999, "Listening to communities: locality research and planning" Urban Studies, 36 1181-1193

Norris C, 1985, The Contest of Faculties: Philosophy and theory after Deconstruction (Methuen, London)

Newcastle City Council, 1998a, Communication Strategy: City West DCP (Newcastle City Council)

Newcastle City Council, 1998b, Newcastle Urban Strategy: the Strategy, a 25 Year Revitalisation Plan for Newcastle (Newcastle City Council) 
Phelps N, Tewdwr-Jones M, 2000, "Scratching the surface of collaborative and associative governance: identifying the diversity of social action in institutional capacity building" Environment and Planning A 32 111-130

Rein M, Schon, D, 1993, "Reframing policy discourse" in The Argumentative Turn in Policy Analysis and Planning Eds F Fischer. J Forester (Duke University Press, Durham, NC) pp 213-233

Sager T, 1994 Communicative Planning Theory (Avebury, Aldershot, Hants)

Sandercock L, 1998, Towards Cosmopolis (Wiley \& Sons, Chichester)

Sanderson I, 1999, "Participation and democratic renewal: from ‘instrumental’ to 'communicative’ rationality" Policy and Politics 27 325-41

Sunley P, 1999, "Space for stakeholding? Stakeholder capitalism and economic geography" Environment and Planning A 31 2189-2205

Taylor N, 1998, "Mistaken interests and the discourse model of planning" Journal of the American Planning Association 64 64-75

Tewdwr-Jones M, Allmendinger P, 1998, "Deconstructing communicative rationality: a critique of Habermasian collaborative planning" Environment and Planning A 30 1975-89

Tewdwr-Jones M, Thomas H, 1998, "Collaborative action in local plan-making: planners' perceptions of 'planning through debate"' Environment and Planning B 25 $127-44$

Throgmorton J, 1993, "Survey research as rhetorical trope: electric power planning arguments in Chicago" in The Argumentative Turn in Policy Analysis and Planning Eds F Fischer, J Forester (Duke University Press, Durham, NC) pp 117-145 Young IM, 1990, Justice and the Politics of Difference (Princeton University Press, Princeton, NJ) 
TABLE 1 - TIMELINE OF THE PARTICIPATION PROCESS: DCP40

\begin{tabular}{|c|c|}
\hline March & - CBD Workshop 1 \\
\hline March-April & $\begin{array}{l}\text {-Series of technical group meetings to determine how to progress CBD } \\
\text { workshop outcomes }\end{array}$ \\
\hline May & $\begin{array}{l}\text {-Report to Council on workshop outcomes } \\
\text {-CBD Workshop } 2 \text { to seek support for technical group outcomes and agree to } \\
\text { criteria for developing City West DCP } \\
\text {-Urban design consultants engaged to input into DCP }\end{array}$ \\
\hline June & $\begin{array}{l}\text {-Report to Council endorsing workshop outcomes and framework for DCP } \\
\text {-Consultants engaged to undertake economic analysis of draft DCP }\end{array}$ \\
\hline August & $\begin{array}{l}\text {-Draft DCP placed on display } \\
\text {-Workshop with Council }\end{array}$ \\
\hline August-October & $\begin{array}{l}\text {-Public exhibition, two drop-in centres, distribution of } 8000 \text { pamphlets, hotline } \\
\text { for public inquiries, briefings with community and business groups, } \\
\text {-Media coverage }\end{array}$ \\
\hline October-November & -Assessment of 36 submissions on draft DCP \\
\hline November & $\begin{array}{l}\text {-Report to Council on submissions } \\
\text {-Responding to issues raised in submission } \\
\text {-Workshop with Council on suggested solutions }\end{array}$ \\
\hline December & $\begin{array}{l}\text {-Workshop with Council } \\
\text {-Report to Council for adoption of DCP } \\
\text {-Workshop with Council } \\
\text {-Council adoption of DCP }\end{array}$ \\
\hline
\end{tabular}


FIGURE 1

DCP 40 AND THE HONEYSUCKLE SITE, INNER NEWCASTLE, NSW 
